The relation of foshagite to $\beta$-monocalcium silicate is somewhat analogous to that of members of the chondrodite series to olivine; the two minerals could be regarded as the first two members of a series with general formula $\mathrm{Ca}_{3}+n \mathrm{Si}_{3} \mathrm{O}_{8}(\mathrm{OH})_{2 n}$. It is structurally possible that more basic members of this series may exist and hillebrandite $\left(2 \mathrm{CaO} \cdot \mathrm{SiO}_{9} \cdot \mathrm{H}_{2} \mathrm{O}\right)$ may be the member with $n=3$; this hypothesis is being investigated. The erystal structure of foshagite was briefly described at the symposium on "Kristallchemie und Strukturanalyse", Berlin, March 1958, and a full account will later be published elsewhere.

$$
\begin{aligned}
& \text { J. A. GARD } \\
& \text { H. F. W. TAYLOR }
\end{aligned}
$$

Department of Chemistry,

University of Aberdeen. Oct. 20.

${ }^{1}$ Gard, J. A., and Taylor, H. F, W., Amer. Mineralogist, 43, 1 (1958) ${ }^{2}$ Dernberger-Schiff, K., Liebau, F., and Thilo, ..., Acta Cryst., 8, $752(1955)$. Mamedov, Kh. S., and Belov, N. V., Doklady Akad.
Nauk S.S.S.R., 107, $463(1956)$. Buerger, M. J., Proc. U.S. Nat. Acad. Sci., 42, 113 (1956). Tolliday, J., Nature, 182, 1012(1958).

\section{Electron Affinity of Atomic Lithium}

RECENT measurements ${ }^{1}$ of some atomic electron affinities based on observations of the optical threshold for electron detachment give rise to a need for theore. tical calculations of electron affinities for comparison. However, none of the empirical extrapolation methods has a justifiable theoretical basis for the extension from atoms and positive ions with attractive Coulomb fields to negative ions with fields of short range. In the case of $\mathbf{H}^{-}$the extrapolated value ${ }^{2}$ of the electron affinity is in good agreement with the value obtained by quantum-mechanical calculations ${ }^{3}$, but in the case of $\mathrm{Li}^{-}$the question still remains unanswered.

Geltman 4 has used the value electron affinity $(\mathrm{Li})=$ $0.384 \mathrm{eV}$, obtained by a quadratic extrapolation procedure with spectroscopic data on isoelectronic systems, for the threshold in his theoretical calcula. tions of the continuous absorption coefficients of $\mathrm{Li}^{-}$. This value does not agree with other estimated values (Ta-You $\mathrm{Wu}^{5}, 0.90$ eV.; Moiseiwitsch ${ }^{6}$, $0.74 \mathrm{eV}$.; and Holøien $\left.{ }^{7}, 0 \cdot 75 \mathrm{eV}.\right)$.

The Ritz variational principle is a method fre. quently used for determining the electron affinity as the difference in potential energy between the groundstate of the atom and the ground-state of the negative ion. The limit to which a given choice of potential parameters makes the energy converge may be used as a criterion for the reliability of the results obtained.

However, such a calculation minimizing the energy in the Ritz variational procedure is difficult and tedious to carry out when applied to the four-electron $\mathrm{Li}^{-}$ion, but in view of the facts mentioned above, a variational determination of electron affinity $(\mathrm{Li})$ is very important. Fortunately, much progress is made by using an electronic computer in evaluating the matrix elements and solving the secular equation.

The purpose of this communication is to direct attention to results already obtained by variational calculation of the energy of $\mathrm{H}^{-}$in the $(2 s)^{2}{ }^{1} S$ state using a 20-parameter function ${ }^{8}$. If we neglect in $\mathrm{Li}^{-}$ the inter-shell interaction and consider the $K$-shell as essentially at the nucleus, the variational procedure is identical with that for the $(2 s)^{2}{ }^{1} S$ state of $\mathrm{H}-$. By using the data quoted in Table 3 , ref. 8 , for $\mathbf{H}^{-}$, the electron affinity $E\left(\mathrm{Li} \rightarrow \mathrm{Li}^{-}\right)=0.81 \mathrm{eV}$. is obtained in good agreement with the estimated results ${ }^{5-2}(1 \mathrm{eV} .=$ $\left.8066.0 \mathrm{~cm}^{-1}\right)$. As an interesting comparison the data for helium quoted in the same table give $E\left(\mathrm{Be}^{+} \rightarrow \mathrm{Be}\right)=8.12 \mathrm{eV}$. (the observed value is $8.89 \mathrm{eV}$.).

Of course, when taking into account the repulsion of electrons with parallel spin by the penetration of the $L$-electrons into the charge distribution due to the $K$-electrons, the above electron affinity will be reduced; but by how much? It is hoped that a variational calculation applied to the ground-state of $\mathrm{Li}^{-}$by using a $20 \times 20$ matrix built up from the same configurations for the $L$-electrons as in ref. 8 will answer this question. Further work along these lines is now in progress.

\section{E. HoLøIEN}

\section{Institute of Theoretical Physics,} University of Oslo.

$$
\text { Nov. } 14 .
$$

'Smith, S. J., and Branscomb, L. M., J. Res, Nat. Bur. Stand., 55, 165 (1955).

${ }^{2}$ Branscomb, L. M., "Negative Ions" in "Advances in Electronics and Electron Physics", 9 (Academic Press, New York, 1957).
and ${ }^{3}$ Heinrich, L. R., Astrophys. J., 99, 59 (1943). Hylleraas, E. A., and Midtdal, J., Phys. Rev., 103, 829 (1956); 109, 1013 (1958). ${ }^{4}$ Geltman, S., Phys. Rev., 104, 346 (1956).

- Wu, T. Y., Chin. J. Phys., 5 (1944); 6 (1945).

6 Moiseiwitsch, B. L., Proc. Phys. Soc., A, 67, 25 (1954).

'Holøien, E., Arch. Math. Naturvidenskab., 52, Nos. 1-2, 74 (1954). ${ }^{8}$ Holøien, E., Proc. Phys. Soc., A, 71, 357 (1958).

\section{Improvement in the Magnetic Detecting Power of Iron-cored Search Coils}

Stowly changing magnetic fields have usually peen measured by means of search coils with iron or mumetal cores, connected either to fluxmeters or to galvanometers. In this communication the term 'coiled rod' is employed and means a straight ferromagnetic rod about which a detector-coil is wound. The sensitivity or detecting power of the coiled rod is usually defined as the total number of flux linkages of the winding produced in the coiled rod by a spatially uniform magnetic field of one oersted and is measured in Maxwell-turns per oersted. The advantage of mumetal over iron for the core of the coiled rod has been its high permeability in low magnetic fields, low electrical losses and low coercive force. Any further increase in sensitivity of coiled rods has been obtained either by lengthening the rod and so reducing its demagnetizing factor or by winding on more turns-the latter case being accompanied by a rapid increase in inductance and by increased resistance unless the diameter of the wire in the coil is correspondingly increased, which in turn affects the overall diameter.

It has been found that a very useful increase in sensitivity of a given coiled rod can be obtained by fitting permeable collector cones to the ends of the rod, the vertices of the cones facing towards the centre of the rod. So far as the experiments have proceeded, an eight-fold increase in sensitivity may be obtained. The increase in detecting power appears to be almost linear with diameter of cone up to the largest tested ( 1.5 times the length of the rod), the detecting power being increased by a factor $K$ :

$$
K=\left(1+n \frac{D}{l}\right)
$$

where $n$ is about 6 for cone diameters $(D)$ less than half the length $(l)$ of the rod, and 5 for larger cones. A good working approximation for the whole range of $D$ up to $1.5 l$ (and perhaps beyond) boing: 